\title{
Uluslararası Ticaret Akımlarının Oynaklığı: ASEAN Serbest Ticaret Anlaşması Üyeleri Örneği
}

(Araştırma Makalesi)

\author{
Volatility of International Trade Flows: Case of ASEAN Free Trade
}

Agreement Members

Doi: 10.29023/alanyaakademik.483909

\section{Yağmur SA ĞLAM}

Dr. $\ddot{O} \breve{g r}$. Üy., Sinop Üniversitesi, Boyabat İBF, İktisat Bölümü, yagmur.saglam@sinop.edu.tr, Zincirlikuyu Mah., 57200,Türkiye.

Orcid No: 0000-0001-6465-0297

Bu makaleye atıfta bulunmak için: Sağlam, Y. (2019). Uluslararası Ticaret Akımlarının Oynaklı̆ğ: ASEAN Serbest Ticaret Anlaşması Üyeleri Örneği. Alanya Akademik Bakış, 3(1), 85-97.

\begin{abstract}
ÖZET
Anahtar kelimeler:

ASEAN,

Uluslararası Ticaret

Akımları,

Oynaklık

Makale Geliş Tarihi:

10.11.2018

Kabul Tarihi:

03.01.2019

Bu çalışmada ASEAN serbest ticaret anlaşmasına taraf olan ve ticaret tarifelerinde indirime giden on ülke için 1990-2017 yıllarını kapsayan bir dönemde yıllı veriler ve panel veri teknikleri ile uluslararası ticaret akımlarının oynaklı̆̆ test edilmiştir. Uygulamadan elde edilen sonuçlara göre ithalat ve ihracat bileşenleri arasında döngüsel bir ilişki vardır ve ekonomik büyüme değişkenine göre daha oynak oldukları ortadadır. Ekonomik büyümeden net ticarete doğru bir nedensellik olduğu tüm panel veri seti için söylenebilirken ülkeler özelinde Laos, Myanmar, Filipinler, Tayland ve Malezya'da uluslararası ticaret akımları oynaklığının nedeninin ekonomik büyümeden kaynaklandiğ iddia edilememektedir. Ayrlca ticaret akımları değişken yani volatildir, çünkü ihracat ve ithalat hem kendi içlerinde hem de ayrı ayrı ekonomik büyüme oranı ile eş-bütünleşiktir ve dolayısıla birlikte hareket ettikleri görülmüşı̈̈r.
\end{abstract}

Keywords:

ASEAN, International Trade

Flows,

Volatility

\section{ABSTRACT}

In this study, the volatility of international trade flows have been tested in a period covering 1990-2017 for the ten members of ASEAN free trade agreement with annually indicators and panel data techniques. According to the results obtained from the empirical part, there is a cyclical relationship between import and export components and they are more volatile than economic growth variable. While it can be seen for the whole panel data set that there is a causality from economic growth towards net trade, it cannot be claimed that the volatility of trade flows in Laos, Myanmar, Philippines, Thailand and Malaysia in particular is due to economic growth. Moreover, exports and imports are co-integrated both within themselves and separately by the economic growth rate, and thus they are moving together so international trade flows are not stable and uncertain. 


\section{GİRIŞ}

Abbott (2000)'e göre iş planlamacıları, genellikle işlemlere uygulanacak kuralların önceden bilindiği istikrarlı ekonomik koşullar altında faaliyet göstermeyi tercih ederler. Açık bir ekonomide, hükümetler işçilerin ve firmaların küresel piyasalardaki oynaklıklardan izole edilmesi için büyük bir baskıyla karşı karşıya kalmaktadırlar. Bu nedenle, hükümetler yatırımcılar için risk olasılığını minimuma indirmek için bölgesel ve iki taraflı (ya da tercihli) ticaret anlaşmaları kabul edilmektedir.

Büyük sakinlik döneminden (1970’ler-1980'lerden) sonra özellikle 1990-2008 döneminde milli gelir ve ticaret akımlarında oynaklığın azaldığı vurgulanmaktadır. Ancak 2008 yılından sonra yaşanan küresel ekonomik gelişmeler "volatilite-oynaklık" kavramının ve analizlerinin önem kazanmasına neden olmuştur. Özellikle ticari büyüme oranları sert bir şekilde inişe geçmiştir.

Barkoulas vd. (2002), ihracatçıların davranışlarını anlamak için ticaret akışlarının seviyesine ek olarak ticaret akışlarının oynaklığını araştırmak gerektiğini öne sürmektedir. Ticaretin volatilitesi toplam çıktı miktarına kıyasla daha oynak olmasına rağmen, genellikle GSYH'den iki ya da üç kat daha oynaktır ve sabit yatırım harcamaları kadar değişkenlik göstermektedir. Bennet vd. (2016), yatırımlardan sonra toplam talep bileşenlerinden en oynak (istikrarsız) olanları ihracat ve ithalattır. Ayrıca ihracat ve ithalatın milli gelirinde en oynak bileşenleri olduğu kabul edilmektedir. Dolayısıyla ticaret oynaklığı, milli gelir hareketleri ile yakından ilintilidir. En azından finansal küresel krize kadar varsayıldığı şekilde bir seyir izlemişlerdir. di Giovanni ve Levchenko (2009) ise ticari açıklık ve oynaklık arasında pozitif bir korelasyon (ilişki) olduğunu iddia etmektedir.

Alan yazında ticaret oynaklığını ölçmek için üzerinde anlaşılan net bir ölçüt yoktur. Özellikle döviz kurları oynaklığının ticaret üzerine etkilerini inceleyen çalışmalarda zaman serilerinin seçili dönem için varyanslarını hesaplama yöntemine gidilmiştir (Rose, 2005). Ancak bu yöntem beklenmeyen şokların etkisini dikkate almamaktadır. Mainsfield ve Reinhardt (2008); ticaret oynaklığı analizlerinde en çok tercih edilen değişken ihracat serisi olduğunu ifade etmektedir. İkinci sırada tedarikçinin ithalatçı piyasadaki ihracat payı (\%) ve son olarak ticaret anlaşmalarının ticaret oynaklığı üzerindeki etkisini anlamak için yıllık reel ihracat hacmidir. Bunun yapılmasında ki amaç yıldan yıla ihracat akımlarında meydana gelebilecek bir çöküş olasılığının ticaret kurumları tarafından bertaraf edildiğinin varsayılmasındandır.

Engel ve Wang (2008)'e göre yapışkan fiyat (sticky prices) varsayımı yapılan bir modelde, talepteki değişimler toplam çıktıda değişikliklere yol açabilir ve bu nedenle uluslararası yayılma için bir kanal oluşturabilir. Bu kanallar mevcut Dinamik Stokastik Genel Denge Modellerinde mevcut olsa da, güçlü değillerdir. Çünkü bu modeller ithalat ve ihracattaki büyük döngüsel (procyclical) hareketleri hesaba katmamaktadır. Genel olarak, refah etkisi ve ticarete konu malların fiyatlarındaki düşüşün etkisi, yabancı malların, yerel mallara göre fiyatlarının yükselmesine rağmen, ithalat talebinde artışa neden olmaktadır. Nitekim, toplam ithalat harcamaları ihracatın değerinden daha fazla artarak ticaret dengesinde bir azalmaya yol açmaktadır. Ancak, ithalat harcamalarındaki bu artışın bir kısmı ithalatın artan fiyatından kaynaklanmaktadır. Bu durum ithalat ve ihracat miktarları arasında döngüsel hareketlere yol açmaktadır. Beaudry ve Portier (2005)'e göre ortak (ülkeler arası) verimlilik şoklarının bileşeni, varyansın küçük bir bölümünü oluşturabilir ve bunun nedeni karar birimlerinin gelecekteki ortak bileşen hakkında güçlü sinyaller almasıdır. Eğer haberler iş çevrimlerinin 
(business cycles) sürdürülmesine yardımcı oluyorsa verimlilik şoklarının bileşeni hakkında verilecek bilgiler de ülkeler arası iş çevrimlerinin yüksek korelasyonuna katkıda bulunabilmektedir. Zimmermann (1999), GSYH bileşenlerinin davranışlarını açıklamak ve bir yandan da ticaret akışlarını rasyonalize etmek için gerçek bir uluslararası iş döngüsü modeli sunmuştur. Ticaret akışlarının yatırımlar kadar değişken olduğunu ifade etmektedir.

Bu çalışmada ASEAN (Güney Doğu Asya Ülkeleri Birliği) Serbest Ticaret Anlaşması (AFTA)'ya taraf olan ülkeler için (gözlemciler hariç) uluslararası ticaret akımlarının oynaklığı 1990-2017 yıllarına ait Dünya Bankası Gelişim Göstergeleri veri tabanından elde edilen yıllık veriler ile analiz edilmiştir. Bu ülkeler; Vietnam, Laos, Filipinler, Kamboçya, Myanmar, Malezya, Endonezya, Singapur, Tayland ve Brunei'dir. Bu ülke grubu üzerine daha önce sadece uluslararası ticaret akımlarının volatilitesini ölçen herhangi ampirik bir çalışma yapılmamıştır. Ayrıca ticaret akımları oynaklığını panel veri teknikleri ile test eden bir çalışmada henüz literatürde mevcut değildir. Çalışmanın gerek ele aldığı ülke grubu gerekse metodoloji bakımından alan yazına ampirik katkı yapması beklenmektedir. Dört bölümden oluşan bu çalışmada ilk bölüm teorik bağlamda ticaret akımlarının bileşenlerine ve oynaklık kavramına açıklık getirmektedir. İkinci bölüm literatürde bu konuda var olan nitel ve nicel çalışmalara değinmektedir ancak çalışma sayısı azdır. İzleyen bölüm veri seti, yöntem ve uygulama bulgularına yer verirken sonuç kısmında elde edilen ampirik bulgular iktisaden yorumlanmıştır.

\section{ALAN YAZIN}

Alan yazında yer alan çalışmalara geçmeden önce bu analize konu olan AFTA (ASEAN Serbest Ticaret Antlaşması) ile ilgili kısa bir bilgi vermek yerinde olacaktır. AFTA bir ticaret bloğudur ve yerel ticaret ile imalat sanayini desteklemek amacıyla hayata geçmiştir. Ayrıca ekonomik ve bölgesel bütünleşme ile uluslararası işbirliklerine de katkıda bulunmaktadır. 1992 yılı Ocak ayında Singapur'da ilk olarak altı ülke ile yola çıkan AFTA şu anda gözlemcilerle beraber on dokuz ülkeyi kapsamaktadır. Aralarında yalnızca on tanesi karşılıklı ticarette tarifeleri kaldırmıştır. Öncelikli amaçları AFTA'yı imzalayanlar arasında tarife ve tarife dışı engellerin azaltılması ve ASEAN bölgesine doğrudan yabancı yatırım çekebilmektir.

Baum ve Çağlayan (2008), 1980:01-2006:12 yılları arasında döviz kuru belirsizliğinin, ticaret akımları oynaklığı üzerine etkisini Avro alanı, yeni sanayileşen ülkeler (NICs) ve diğer sanayileşmiş ülkeler için analiz etmişlerdir. GARCH ve GARCH-M testleri ile aylık veriler (karşılıklı toplam reel ihracat, reel GSYH, ihracat fiyat deflatörü, tüketici fiyat endeksi ve spot döviz kurları) incelenmiştir. Ampirik modele göre Avro alanı üyesi olmak döviz kuru oynaklığının ticaret akımları oynaklığına etkisinden kaçınmaya yeterli olmamıştır. Döviz kuru belirsizliği karşılıklı ticaret akımları üzerinde pozitif ve kalıcı bir etki bırakmaktadır. Ancak döviz kuru belirsizliği, diğer endüstrileşmiş ülkelerin veya NICs'lerin ticaret akışlarının hacmini etkilememektedir. $\mathrm{Bu}$ durum ihracatçı ve ithalatçıların davranışlarını önemli ölçüde etkilemektedir.

Mansfield ve Reinhardt (2008), serbestleşme ve deniz aşırı ticari akımları artırmak amaçlı kurulan uluslararası ticari enstitüler; piyasa aktörleri fiyat istikrarını tercih ettikleri için, ticaret kurumları ticaret oynaklığını azaltarak dış ticaret hacmini artırmaktadır. 1995-2001 yıllarına ait yıllık veriler ile yaptıkları ampirik çalışmadan (ARCH ve ARCH-M testleri ile) elde edilen bulgular; Correlates of War Project (2003) çalışmasındaki ülkeler ile yazarlar 
tarafindan veri setine eklenen Hong Kong ve Makao (162 ülke) için Dünya Ticaret Örgütü gibi ve Tercihli Ticaret Anlaşmalarının (PTAs), ihracat oynaklığını önemli ölçüde azalttığını göstermektedir.

Engel ve Wang (2008), 25 OECD ülkesi için dönemsel verilerle 1973Q1-2006Q3 yılları arasını dayanıklı mal ticaretinin oynaklığını çok yönlü bir şekilde analiz etmişlerdir. Standart modeller ile kendi kurdukları model arasında karşılaştırma yapan çalışmada 2 sektörlü ve 2 ülkeli bir model varsayımına gidilmiştir ve Backus-Smith Yapbozu ile test edilmiştir. Ampirik bulgular; ithalat ve ihracatın GSYH'ye oranla yaklaşı üç kat daha oynak olduğunu; ithalat ve ihracatın döngüsel (procyclical) ve birbirleriyle pozitif ilişkili olduğunu; net ihracatın konjonktör karşıtı, üretim artarken azalan bir seyir (countercyclical) izlediğini iddia etmektedir.

Rahutami (2013), döviz kuru istikrarsızlığının ticaret üzerine etkisini 2001-2011 yıllarını içeren bir veri seti için panel regresyon tekniği ile analiz etmiştir. On ASEAN ülkelesini ele aldığ 1 çalışmasında döviz kuru volatilitesinin ne ihracat ne de ithalat üzerinde anlamlı bir etkisi olmadığını ifade etmiştir.

Soleymani vd. (2015), ASEAN-4 ülkeleri için onların beş ticaret partneri için döviz kuru oynaklığının ticaret akımları üzerine etkisini 1980-2012 yılları arasında test etmişlerdir. Yıllık ihracat ve ithalat verileri ile yaptıkları analizden (4 ayrı model kurmuşlardır) elde edilen bulgulara göre uzun ve kısa dönemde döviz kuru istikrarsızlığının ticaret akımları üzerine negatif bir etkisi vardır.

Prajakschitt (2015), Çin'e ait döviz kurunda meydana gelen bir oynaklığın ASEAN-6 ülkelerinin ticaret akımları üzerine olan etkisini analiz etmiştir. 2001-2013 yıllarına ait veriler çekim modeli ve sabit etkiler modeli ile test edilmiştir. Elde edilen en çarpıcı sonuç hem seçili ülkeler hem de Çin için reel döviz kuru ve ticaret akımları arasındaki ilişki istatistiki olarak anlamsizdir.

Bennett vd. (2016) milli gelir ve ticaret akımları oynaklığını bileşenlerine ayrıştırdıkları kapsamlı çalışmalarında 1990-2011 dönemini analiz etmişlerdir. Seçtikleri ülkeler ticaret rejimlerini 1985 sonrası serbestleştirmiş olanlardır ve yıllık veriler UN COMTRADE 4-dijit SITC Rev. 2 veri bankasından elde edilmiştir. Elde edilen sonuçlara göre; ticari büyüme oynaklığı büyük ölçüde tüm ülkeler için ortak bir faktöre atfedilebilir. Ülkeye özgü faktörlerin (country spesific factors) genel ticaret oynaklığı, ortak faktörden (common factor) daha küçük de olsa, büyük bir kapsama sahip olduğu görülmektedir. Buna karşllık, ürün ve ortakların etkileri toplam ticaret oynaklığı üzerinde göz ardı edilebilir bir etkiye sahip gibi görünmektedir.

Pino vd. (2016), 1974-2011 yıllarını kapsayan bir veri seti ile Malezya, Singapur, Kore Cumhuriyeti, Tayland, Filipinler ve Endonezya için döviz kuru volatilitesinin ihracat üzerine etkilerini analiz etmişlerdir. GARCH ve hareketli ortalamalar standart hata testlerinin kullanıldığı uygulamadan elde edilen sonuçlara göre hem uzun hem de kısa dönemde döviz kuru oynaklığının ihracat üzerine etkisi vardır ancak ülkeden ülkeye bu etki değişmektedir.

\section{VERİ SETI, YÖNTEM ve UYGULAMA BULGULARI}

Analize dahil edilen [GSYH büyüme oranı (\%)-GRW, ithalat-IMP ve ihracat (büyüme oranları \%)-EXP, net ihracat-NT (logaritması alınmıştı)] değişkenler Engel ve Wang (2008) 
çalışmasından yola çıkılarak seçilmiştir. Öncelikle değişkenliklerin standart hataları karşılaştırılmış ve böylece hangisinin oynaklığının daha yüksek olduğuna bakılmış daha sonra durağanlık testleri yapılmıştır. Ardından teorinin iddia ettiği şekilde ithalat ve ihracatın birbirleriyle ve GSYH oranı ile ilişkili olup olmadıkları yani beraber hareket edip etmediklerini anlamak için eş-bütünleşme testi yapılmıştır. Son olarak ta ticari büyüme (net ihracat) ve çıktı oranı arasındaki eş-bütünleşmeye ve nedenselliğin yönüne bakılmıştır.

Tablo 1. Değişkenlere ait tanımlayıcı istatistikler

\begin{tabular}{ccccc}
\hline & EXP & GRW & IMP & NT \\
\hline \hline Mod & 27.57239 & 5.120033 & 24.81352 & $-1.71 \mathrm{E}+09$ \\
Medyan & 11.96284 & 6.021877 & 13.28505 & 19.77047 \\
Maksimum & 425.0412 & 15.24038 & 379.9677 & 25.11687 \\
Minimum & -31.80498 & -34.80864 & -40.67524 & $-3.17 \mathrm{E}+10$ \\
Std. Hata & $\mathbf{6 2 . 8 2 7 8 0}$ & $\mathbf{5 . 5 6 8 3 6 5}$ & $\mathbf{4 9 . 9 1 2 0 2}$ & $\mathbf{4 . 0 1 E + 0 9}$ \\
Çarp1kl1k & 4.137828 & -3.810162 & 4.633656 & -3.831788 \\
Basiklık & 21.41804 & 25.41694 & 28.94512 & 22.16509 \\
& & & & \\
Jarque-Bera & 4756.623 & 6540.201 & 8855.378 & 4970.364 \\
Prob. Değeri & $\mathbf{0 . 0 0 0 0 0 0}$ & $\mathbf{0 . 0 0 0 0 0 0}$ & $\mathbf{0 . 0 0 0 0 0 0}$ & $\mathbf{0 . 0 0 0 0 0 0}$ \\
\hline
\end{tabular}

Tablo 1'e göre; değişkenlerin tamamı normal dağılıma sahiptir. Çünkü J-B (Jarque Bera) test istatistiğine sahip olasılık değerleri \% 5'te istatistiki olarak anlamlıdır. Ayrıca ihracat ve ithalatın standart hata değerleri ekonomik büyüme oranından büyüktür. $O$ halde ihracat büyümeye göre $12 \mathrm{~kat}$, ithalat büyümeye göre $10 \mathrm{~kat}$ daha volatildir. Örnekleme ait mod ve medyan değerleri birbirlerine çok yakın değillerdir. Bu durum değişkenlerin oynaklık yapısından kaynaklanmaktadır.

Yatay kesitler arasındaki homojenlik ilişkisini görmek adına ilk olarak Delta testi değişkenlere uygulanmıştır (Pesaran ve Yamagata 2008, 52);

$y_{i t}=a_{i} \tau_{T}+X_{i} \beta_{i}+\varepsilon_{1, i}$

$\tau_{T}, T x 1$ vektörünü ifade etmektedir. $\beta_{\mathrm{i}}$ ise bilinmeyen eğim katsayısı $k x 1$ vektörüdür,

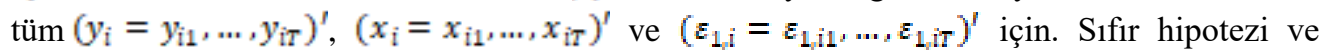
alternatifi aşağıdaki şekilde ifade edilmektedir;

$H_{0: \beta_{i}}=\beta$

$H_{1}: \beta_{i} \neq \beta_{j}$

Tablo 2. Homojenlik Testi

\begin{tabular}{|c|c|c|}
\hline Delta Testi & Test istatistikleri & Olasılık (Prob.)Dĕgeri \\
\hline$\widehat{\Delta}$ & -1.394 & 0.918 \\
\hline$\hat{\Delta}_{a d j}$ & -1.532 & 0.937 \\
\hline
\end{tabular}

Tablo 2'ye göre hem küçük örneklem $(\triangle)$ hem de büyük örneklemi temsil eden $\left(\Delta_{a d j j}\right)$ test istatistiklerine ait olasılık değerleri \% 5 'te istatistiki olarak anlamsızdır. $O$ halde serilerin homejen olduğunu iddia eden sıfir hipotezi kabul edilmektedir. 
Birim kök testine geçmeden yatay kesit birimleri arasında bağımlılık olup olmadığı $\mathrm{CD}_{\mathrm{LM}}$ testi ile analiz edilmiştir (Pesaran 2004, 3);

$y_{i t}=\alpha_{i}+\beta_{i} x_{i t}+\varepsilon_{2 \text { it }}$ tüm $i=1,2, \ldots, N$ ve $t=1,2, \ldots, T$ için

$i$ her bir yatay kesit birimini temsil etmektedir. $t$ ise panelin zaman boyutunu göstermektedir. $\quad x_{i t}$ zamanla değişen regresörlere ait gözlemlenen $k x 1$ vektörüdür, $\alpha_{i}$ bireysel kesitlere ait sabit katsayıları, $\beta_{i}$ aynı şekilde birimlere ait eğim kaysayılarını ifade etmektedir. Alternatif ve sıfır hipotezi şu şekilde belirtilmektedir;

$$
\begin{aligned}
& H_{0:}: \rho_{i}=\rho_{j i}=\operatorname{cor}\left(\varepsilon_{2, i t}, \varepsilon_{2, j \mathrm{j}}\right)=0 \\
& \mathrm{H}_{1}: \rho_{\mathrm{ij}}=\rho_{\mathrm{ji}} \neq 0
\end{aligned}
$$

Tablo 3. Yatay-Kesit Bağımsızlığı Testi

\begin{tabular}{|l|lc|}
\hline & Test Íst. & Prob. \\
\hline$C D_{L M 1}(\mathrm{BP}, 1980)$ & 75.659 & $0.003^{*}$ \\
$C D_{L M 2}($ Pesaran 2004) & 3.232 & $0.001^{*}$ \\
$C D_{L M}($ Pesaran 2004 CD) & 0.187 & 0.426 \\
\hline
\end{tabular}

(*) \% 5 güven aralığında istatistiki olarak anlamlılığı ifade etmektedir. Tablo 3'e göre Breusch-Pagan ve $\left(C D_{\text {LM2 }}\right.$ Pesaran 2004 test istatistiklerine ait olasılık değerleri anlamlıdır. Dolayısıyla yatay kesit birimleri arasında bağımszılık olduğunu iddia eden sıfır hipotezi reddedilmektedir.

Eş-bütünleşme testinde önce Pesaran vd. tarafindan geliştirilen yatay kesit bağımsızlığını ve Çok Faktörlü Hata Yapısı'nı dikkate alan bir panel birim kök testi değişkenler için tek tek uygulanmıştır. İki ayrı test istatistiğinin hesaplandığı bu analizde CIPS; yatay kesit birimlerine uyarlanmış panel birim kök test istatistiğini, CIBS; ise Sargan-Bhargava yatay kesitlere uyarlanmış basit ortalamalar test istatistiğini ifade etektedir. Temelde bu test ile amaçlanan makro ekonomik göstergeler (çıktı, işsizlik, faiz oranları, yatırım oranları vb. gibi) ile yapılan modellemelerde değişkenlere ait ortak faktörlerin hata terimleri arasındaki otokorelasyonun elimine edilmesidir.

Test istatistikleri ifade edilen şekilde hesaplanmaktadır (Pesaran vd. 2013, 96);

$C I P S_{N T}^{*}=N^{-1} \Sigma_{\bar{I}-1}^{N} t_{i}^{*}(N, T)$

$$
C S B_{N T}=N^{-1} \sum_{i-1}^{N} C S B_{i}(N, T)
$$

$\mathrm{N}$ yatay kesit birimlerini ve $\mathrm{T}$ zaman boyutunu temsil etmektedir. $t_{\mathrm{i}}^{*}\left(N_{s} T\right)$ örnekleme ait dağılımı vermektedir. Sıfır hipotezine göre tüm $i$ 'ler $(1,2,3, \ldots, N)$ için $H_{0}: \beta_{i}$ yatay kesit birimlerinde birim kök yoktur (Pesaran vd. 2013, 99). CSB test istatistikleri stokastik simülasyon tekniği ile hesaplanmaktadır. $\mathrm{Bu}$ nedenle, CIPS test istatistiklerine göre daha güvenilir ve üstün sonuçlar vermektedir. 
Tablo 4. Birim Kök Testi Sonuçları

\begin{tabular}{|c|c|c|c|c|c|}
\hline & \multicolumn{2}{|c|}{ Sabitli Model } & \multicolumn{2}{|c|}{ Sabit ve Trendli Model } \\
\hline & $\begin{array}{c}\text { Gecikme } \\
\text { Sayıs1 }\end{array}$ & İstatistikler & $\begin{array}{c}\text { Kritik Değer } \\
(\mathrm{k}=3) \\
(\% 10)\end{array}$ & İstatistikler & $\begin{array}{l}\text { Kritik Değer } \\
(\mathrm{k}=3)(\% 10)\end{array}$ \\
\hline CIPSm & 0 & $-2.590 *$ & -2.68 & $-2.656^{*}$ & -3.05 \\
\hline \multirow[t]{4}{*}{ GRW } & 1 & $-1.371^{*}$ & -2.50 & $-1.365^{*}$ & -2.83 \\
\hline & 2 & $-0.476^{*}$ & -2.20 & $-0.748^{*}$ & -2.47 \\
\hline & 3 & - & -1.98 & - & -2.27 \\
\hline & 4 & - & - & - & - \\
\hline CSBM & 0 & 0.040 & 0.307 & 0.029 & 0.109 \\
\hline \multirow[t]{4}{*}{$G R W$} & 1 & 0.097 & 0.232 & 0.062 & 0.087 \\
\hline & 2 & 0.076 & 0.167 & 0.044 & 0.063 \\
\hline & 3 & $0.112 *$ & 0.102 & $0.053 *$ & 0.038 \\
\hline & 4 & $0.102 *$ & 0.049 & $0.036^{*}$ & 0.016 \\
\hline CIPSm & 0 & -3.536 & -2.68 & -3.418 & -3.05 \\
\hline \multirow[t]{4}{*}{$E M P$} & 1 & $-2.030 *$ & -2.50 & $-1.550^{*}$ & -2.83 \\
\hline & 2 & -2.977 & -2.20 & $-2.125^{*}$ & -2.47 \\
\hline & 3 & - & -1.98 & - & -2.27 \\
\hline & 4 & - & - & - & - \\
\hline CSBM & 0 & 0.034 & 0.307 & 0.023 & 0.109 \\
\hline \multirow[t]{4}{*}{ EXP } & 1 & 0.053 & 0.232 & 0.035 & 0.087 \\
\hline & 2 & 0.084 & 0.167 & 0.045 & 0.063 \\
\hline & 3 & $0.105^{*}$ & 0.102 & $0.045^{*}$ & 0.038 \\
\hline & 4 & $0.143^{*}$ & 0.049 & 0.076 & 0.016 \\
\hline CIPSm & 0 & -2.902 & -2.68 & -3.181 & -3.05 \\
\hline \multirow[t]{4}{*}{ DUP } & 1 & $-1.035^{*}$ & -2.50 & $-1.342^{*}$ & -2.83 \\
\hline & 2 & $0.078^{*}$ & -2.20 & $-0.316^{*}$ & -2.47 \\
\hline & 3 & - & -1.98 & - & -2.27 \\
\hline & 4 & - & - & - & - \\
\hline CSBm & 0 & 0.085 & 0.307 & 0.033 & 0.109 \\
\hline \multirow[t]{4}{*}{$M U P$} & 1 & 0.162 & 0.232 & $0.113^{*}$ & 0.087 \\
\hline & 2 & $0.226^{*}$ & 0.167 & $0.105^{*}$ & 0.063 \\
\hline & 3 & $0.313^{*}$ & 0.102 & $0.174 *$ & 0.038 \\
\hline & 4 & $0.217^{*}$ & 0.049 & $0.105^{*}$ & 0.016 \\
\hline CIPSm & 0 & -4.084 & -2.68 & -4.104 & -3.05 \\
\hline \multirow[t]{4}{*}{$\mathbb{N T}$} & 1 & -2.603 & -2.50 & $-2.294 *$ & -2.83 \\
\hline & 2 & $-2.083^{*}$ & -2.20 & $-1.432^{*}$ & -2.47 \\
\hline & 3 & - & -1.98 & - & -2.27 \\
\hline & 4 & - & - & - & - \\
\hline CSBM & 0 & 0.030 & 0.307 & 0.030 & 0.109 \\
\hline \multirow[t]{4}{*}{$\mathbb{N T}$} & 1 & 0.037 & 0.232 & 0.034 & 0.087 \\
\hline & 2 & $0.189 *$ & 0.167 & $0.080^{*}$ & 0.063 \\
\hline & 3 & $0.149 *$ & 0.102 & $0.062 *$ & 0.038 \\
\hline & 4 & $0.168 *$ & 0.049 & $0.090 *$ & 0.016 \\
\hline
\end{tabular}

CIPS ve CSB test istatistiklerine ait tablo kritik değerleri Pesaran vd. (2013) çalışmasından elde edilmiştir. Sayfa 108 tablo B! Ve sayfa 110 tablo B2 sırasıyla sabitli ile sabitli ve trendli modele ait CIPS istatistiklerinin kiritik değerlerini içermektedir. CSB istatistiklerine ait sabitli ve sabitli ile trendli modele ait değerlerse sirasıla sayfa 112 tablo B3 ve sayfa 114 tablo 
B4'te yer almaktadır. Tabloda yer alan (*) sembolü \% 10 güven aralığında test istatistikleri tablo kritik değerlerinden büyük olan değerleri ifade etmektedir. $O$ halde değişkenler düzeyde birim kök içerirken birinci farkları durağandır, I(1)'dir.

Delta testi ve CDlm testlerinde elde edilen sonuçlara göre homojenite ve yatay kesit bağımlılığını birlikte dikkate alan bir eş-bütünleşme testi uygulamak gerekmektedir. DurbinHausmann eş bütünleşme testi Westerlund tarafından 2008 yllında geliştirilmiş ve bahsedilen kriterlerin yanı sıra ortak faktörleri de dikkate almaktadır. Ortak faktörler aşağıda yazılan denklemler ile ifade edilmektedir (Westerlund 2008, 199);

$\Xi_{\text {it }}=\hat{\lambda}_{i} F_{t}+e_{\text {it }}$

$F_{j t}=\rho_{j} F_{j t-1}+u_{j t-1}$

$e_{i t}=\phi_{i} e_{i t-1}+v_{i t}$

$F_{\text {t }}$ ortak faktörü ifade eder and $F_{\text {jt }}$ ise $k$ boyutunda ortak faktöre aittir. 8 numaralı denklemde tüm $j=(1,2, \ldots, k)^{\text {tler }}$ ve $\rho_{j}<1$ iken $(10), F_{t}$ durağandır. DH eş-bütünleşme testine ait hata düzeltme süreci varsayımları aşağıdaki gibidir (Westerlund 2008, 200);

- Tüm yatay kesit birimleri için $\mathbb{V}_{\text {it' }}$ nin ortalaması sıfırdır.

- Tüm yatay kesit birimleri için $E\left(v_{i t} v_{k j}\right)=0 ;(j \neq k, t$ ve $j)$.

$-\operatorname{var}\left(v_{i t}\right)=w_{i}^{2}<\infty$ ve var $\left(w_{i t}\right)>0$ positiftir.

$-E\left(u_{t}\right)=0$ ve $\operatorname{var}\left(u_{t}\right)<\infty$ dir.

$-Y_{\text {it }} \sim I(1)$.

$-X_{\text {it }} \sim I(0), X_{\text {it }} \sim I(1), i \neq j$.

DH testi için iki farklı test istatistiği hesaplanmaktadır. Bunlardan; $D H_{g}$ yatay kesit birimleri heterojen iken ve $D H_{p}$ yatay kesit birimleri homojen iken yorumlamada kullanılmaktadır. Sıfır hipotezi tüm yatay kesit birimleri arasında eş-bütünleşme olmadığını iddia etmektedir.

Tablo 5. Eș-bütünleșme Testi Sonuçları

\begin{tabular}{|c|c|c|}
\hline GRW ve IMP için DH Testi & Test İstatistiği & Prob. \\
\hline$D H_{g}($ grup $)$ & 62.030 & 0.000 \\
\hline$D H_{p}($ panel $)$ & 113.312 & $0.000 *$ \\
\hline IMP ve EXP için DH Testi & Test İstatistiği & Prob. \\
\hline$\overline{D H_{g}(\text { grup })}$ & 650.456 & 0.000 \\
\hline$\overline{D H_{p}(\text { panel })}$ & 275.372 & $0.000 *$ \\
\hline GRW ve EXP için DH Testi & Test İstatistiği & Prob. \\
\hline$\overline{D H_{g}(\text { grup })}$ & 188.651 & 0.000 \\
\hline
\end{tabular}




\begin{tabular}{|l|l|l|}
\hline$D H_{p}($ panel) & 149.767 & $0.000^{*}$ \\
\hline GRW ve DT için DH Testi & Test İstatistiği & Prob. \\
\hline$D H_{g}$ (grup) & 50.803 & 0.000 \\
\hline$D H_{p}$ (panel) & 181.063 & $0.000 *$ \\
\hline
\end{tabular}

Tablo 5' e göre (*) sembolü homojen yatay kesit birimleri arasında eş-bütünleşme olduğunu $\% 5$ istatistiki anlamlılık düzeyinde kanıtlamaktadır. O halde net ticaret ve ekonomik büyüme arasında eş-bütünleşik bir ilişki mevcuttur. Ayrıca ithalat ve ihracat büyüme oranları ile ekonomik büyüme birlikte hareket etmektedir. İtlahat ve ihracat büyüme oranları da eşbütünleşiktir. Sıfır hipotezi reddedilmektedir.

Hatemi-J panel nedensellik testi, yapısal kırılmalar, pozitif ve negatif şoklar gibi istikrarsızlığa neden olan her bir durumun araştırmacılar tarafından hesaba katılmasına olanak tanımaktadır. Granger nedensellik yaklaşımı, bir değişkenin geçmiş değerlerinin bir diğerinin öngörüsünü arttırıp arttırmadığına dayandığı ve asimetrik nedensellik etkilerini ihmal ettiği için eleştirilmektedir (Hatemi-J ve diğerleri, 2015: 3). Uygulamada, karar birimleri aynı tutuma sahip olsalar bile, pozitif şoklardan ziyade negatif şoklara çok farklı reaksiyonlar vermektedirler. Bu test araştırmacıların, özellikle zaman boyutunun (T), gözlem sayılarından (N) daha kısa olduğu durumda veya yatay kesitler arasındaki yayılma etkileri olsa dahi güvenilir sonuçlar vermekte, küreselleşen ekonomide gelişmekte olan ve gelişen piyasalar üzerine yapılan çalışmaların özgürlük derecelerini artırmasına yardımcı olmaktadır (Hatemi-J, 2011: 2-3).

Hatemi-J testi $w_{1}$ ve $w_{2}$ gibi iki değişken arasındaki karşılıklı ilişkiye odaklanmaktadır. Değişkenler arasındaki etkileşim aşağıda ki gibi ifade edilebilir (Hatemi-J ve diğerleri, 2015: 9):

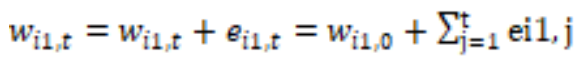

(10)

$w_{i 2, t}=w_{i 2, t}+e_{i 2, t}=w_{i 2,0}+\sum_{j=1}^{t} e i 2_{s} j$

$\mathrm{N}$, yatay kesitlerin sayısını ifade etmektedir. Hata terimi $(e)$ beyaz gürültülüdür, ortalaması sıfırdır ve geçmiş değerleri ile arasında bir bağıntı yoktur. Tüm $i=\mathbb{1}_{w} \ldots, N$ için negative ve pozitif şoklar sirasıyla şu şekilde tanımlanmaktadır; $e_{\mathrm{i} 1, t}^{+}:=\max \left(e_{\mathrm{i} 1, t}, 0\right), e_{\mathrm{i} 2, t}^{+}:=\max \left(e_{\mathrm{i} 2, t}, 0\right)$ ve $e_{\mathrm{i} 1, t}^{-}:=\min \left(e_{\mathrm{i} 1, t}, 0\right), e_{\mathrm{i} 2, \mathrm{t}}^{-}=\min \left(e_{\mathrm{i} 2, t}, 0\right)(12)$

12 numaralı denklemler şokların birikimli toplamlarını elde etmek için kullanılmaktadır. Hatemi-J ve diğerleri (2015), asimetrik panel nedensellik testi VAR-SUR (p) - Vektör Otoregresif Görünüşte İlişkili Olmayan Regresyon (SUR) modelini kullanmaktadır. (p). modelin gecikme sayısını ifade eder ve zaman serisinde ki trendi açıklar. Bunun seçimi, hata koşullarının bağımsız olabileceğini varsaydığı ve verilerin açıklanmasında ya da bir tepkinin doğru olarak tahmin edilmesinde yardımcı olması bakımından önemlidir. En uygun gecikme sırası, bilgi kriterleri ile belirlenmektedir (minimum değere sahip olanı seçilmiştir). Sıfır hipotezi ' $H_{0} w_{\mathrm{i} 2, \mathrm{t}}^{+}$nedeni değildir $w_{\mathrm{i1}, t}^{+}$', şeklindedir. Wald test istatistiği ile sınanmaktadır 
ve Wald testi normallik varsayımına dayanır ve asimptotoik ki-kare $\left(\chi^{2}\right)$ dağılımı göstermektedir (Hatemi-J ve El-Khatib, 2016: 4036). Negatif bileşenler test edildiğinde ' $\left(w_{i 1}^{-}, w_{i 2}^{-}\right)$' ' vektörü kullanılabilir.

Tablo 6. Her Bir Ülke için Panel Nedensellik Testi Sonuçları

\begin{tabular}{|c|c|c|c|}
\hline Ülkeler & SIfır Hipotezi & MWALDistatistiği & Prob. Değeri. \\
\hline Brunei & $\begin{array}{c}G R W^{-} \nRightarrow N N^{+} \\
G R W^{-} \neq N T^{-} \\
G R W^{+} \neq N N T^{+} \\
G R W^{+} \nRightarrow N T^{-}\end{array}$ & $\begin{array}{l}0.753 \\
0.026 \\
0.006 \\
7.562\end{array}$ & $\begin{array}{c}0.386 \\
0.871 \\
0.940 \\
0.006^{*}\end{array}$ \\
\hline Endonezya & $\begin{aligned} G R W^{-} & \neq N T^{+} \\
G R W^{-} & \neq N T^{-} \\
G R W^{+} & \geqslant N T^{+} \\
G R W^{+} & >N T^{-}\end{aligned}$ & $\begin{array}{c}0.895 \\
13.041 \\
0.691 \\
0.355 \\
\end{array}$ & $\begin{array}{c}0.344 \\
0.000 * \\
0.701 \\
0.551\end{array}$ \\
\hline Malezya & $\begin{aligned} G R W^{-} & \geqslant N T^{+} \\
G R W^{-} & \geqslant N T^{-} \\
G R W^{+} & >N T^{+} \\
G R W^{+} & >N T^{-}\end{aligned}$ & $\begin{array}{l}0.590 \\
0.213 \\
0.041 \\
0.183\end{array}$ & $\begin{array}{l}0.442 \\
0.644 \\
0.406 \\
0.669\end{array}$ \\
\hline Filipinler & $\begin{aligned} G R W^{-} & \geqslant N T^{+} \\
G R W^{-} & >N T^{-} \\
G R W^{+} & >N T^{+} \\
G R W^{+} & >N T^{-}\end{aligned}$ & $\begin{array}{l}0.017 \\
2.614 \\
0.691 \\
0.053\end{array}$ & $\begin{array}{l}0.897 \\
0.106 \\
0.840 \\
0.818\end{array}$ \\
\hline Singapur & $\begin{aligned} G R W^{-} & \neq N T^{+} \\
G R W^{-} & \geqslant N T^{-} \\
G R W^{+} & \geqslant N T^{+} \\
G R W^{+} & >N T^{-}\end{aligned}$ & $\begin{array}{l}0.001 \\
1.494 \\
5.325 \\
8.883\end{array}$ & $\begin{array}{c}0.981 \\
0.222 \\
0.021 * \\
0.003 *\end{array}$ \\
\hline Tayland & $\begin{aligned} G R W^{-} & \neq N T^{+} \\
G R W^{-} & \geqslant N T^{-} \\
G R W^{+} & \geqslant N T^{+} \\
G R W^{+} & >N T^{-}\end{aligned}$ & $\begin{array}{l}2.169 \\
0.324 \\
0.771 \\
2.460\end{array}$ & $\begin{array}{l}0.141 \\
0.569 \\
0.380 \\
0.117\end{array}$ \\
\hline Myanmar & $\begin{array}{c}G R W^{-} \neq \geqslant N T^{+} \\
G R W^{-} \neq \geqslant N T^{-} \\
G R W^{+} \neq \geqslant N T^{+} \\
G R W^{+} \neq>N T^{-}\end{array}$ & $\begin{array}{l}0.236 \\
0.684 \\
0.000 \\
1.132\end{array}$ & $\begin{array}{l}0.627 \\
0.408 \\
0.999 \\
0.287\end{array}$ \\
\hline Kamboçya & $\begin{aligned} G R W^{-} & \neq N T^{+} \\
G R W^{-} & >N T^{-} \\
G R W^{+} & >N T^{+} \\
G R W^{+} & >N T^{-}\end{aligned}$ & $\begin{array}{c}2.029 \\
0.010 \\
5.856 \\
11.145\end{array}$ & $\begin{array}{c}0.154 \\
0.922 \\
0.016^{*} \\
0.001^{*}\end{array}$ \\
\hline Laos & $\begin{array}{c}G R W^{-} \neq N N^{+} \\
G R W^{-} \neq N N T^{-} \\
G R W^{+} \neq N N T^{+} \\
G R W^{+} \neq>N T^{-}\end{array}$ & $\begin{array}{l}0.036 \\
0.416 \\
1.576 \\
0.005\end{array}$ & $\begin{array}{l}0.850 \\
0.519 \\
0.209 \\
0.944\end{array}$ \\
\hline Vietnam & $\begin{aligned} G R W^{-} & \geqslant N T^{+} \\
G R W^{-} & \geqslant N T^{-} \\
G R W^{+} & \geqslant N T^{+} \\
G R W^{+} & >N T^{-}\end{aligned}$ & $\begin{array}{l}1.046 \\
8.715 \\
0.678 \\
0.005\end{array}$ & $\begin{array}{c}0.306 \\
0.003 * \\
0.410 \\
0.946\end{array}$ \\
\hline
\end{tabular}


Asimetrik panel nedensellik analizi Tablo 6'dan da görüldüğü gibi 4 farklı mod (şok durumu) için tekrar edilmiştir. $G R W^{+} \neq N T^{+}$ekonomik büyüme, net dış ticaretin (ihracatın) nedeni değildir hipotezini ifade etmektedir. Değişkenler üzerinde yer alan (+) işareti pozitif kümülatif şokları, (-) işareti ise negatif kümülatif şokları temsil etmektedir. (*) sembolü \% 5 'te istatistiki anlamlılığı ifade etmektedir.

Tablo 6'ya göre; ekonomik büyümede meydana gelecek olan pozitif şokların net dış ticaret üzerinde negatif etkilere sebep olduğunu iddia eden sıfır hipotezi Brunei, Singapur ve Kamboçya için kabul edilirken diğer ASEAN serbest ticaret anlaşması üyeler için red edilmektedir. Negatif ekonomik büyümenin yine negative net diş ticaretin nedeni olduğunu iddia eden sıfır hipotezi ise Endonezya ve Vietnam dışında tüm ülkelerde geçersizdir. Singapur ve Kamboçya'da ekonomik büyümeye gelecek olan pozitif kümülatif bir şok net dış ticarette de pozitif bir şoka neden olmaktadır. Laos, Myanmar, Filipinler, Tayland ve Malezya'ya ait olasılık değerleri anlamsız olduğu için bir yorum yapılamamaktadır.

Tablo 7. Tüm Panel için Nedensellik Testi Sonuçları

\begin{tabular}{|c|c|c|}
\hline Sifir Hipotezi & Panel Fisher İst. & Olasılık D. \\
\hline$G R W^{-} ¥ N T^{+}$ & 17.209 & 0.639 \\
$G R W^{-} \neq N T^{-}$ & 40.761 & $0.004^{*}$ \\
$G R W^{+} \neq N T^{+}$ & 25.889 & 0.170 \\
$G R W^{+} \neq N T^{-}$ & 45.515 & $0.001^{*}$ \\
\hline
\end{tabular}

(*) sembolü \% 5'te anlamlılı̆g 1 ifade etmektedir. Tablo 7'de raporlanan ve tüm panel veri seti için elde edilen Fisher test istatistiklerine ait olasılık değerleri Tablo 6'yı doğrulayan sonuçlar vermektedir. Tüm ülkeler için ekonomik büyümeden net diş ticarete doğru bir nedensellik mevcuttur. Ancak karşılaştıkları pozitif ve negatif şokların birbirleri üzerine etkileri farklılaşmaktadır.

\section{SONUÇ}

1990-2017 yılları arasında seçili ülke grubu için ticaret akımları oynaklığının bileşenleri panel veri analizi ile incelenmiştir. Çalışmadan elde edilen ampirik bulgular ticaret akımlarının değişken olduğunu, ihracat ve ithalatın hem kendi içlerinde hem de ayrı ayrı ekonomik büyüme oranı ile eş-bütünleşik oldukları ve dolayısıyla birlikte hareket ettikleri görülmüştür. Ticaret akımlarının volatil olmasının başlıca sebeplerinden biri olarak görülen bu durum Engel ve Wang (2008) çalışmalarından elde ettikleri bulgular ile uyuşmaktadır yani ihracat ve ithalat arasındaki ilişki döngüseldir (procyclical) diyebilirz. Ticaret akımlarının oynaklığının milli gelir ile yakından ilgili olduğu bir kez daha bu çalışma ile ispatlanmıştır.

Ekonomik büyümeden net ticarete doğru bir nedensellik olduğu tüm panel veri seti için söylenebilirken ülkeler özelinde Laos, Myanmar, Filipinler, Tayland ve Malezya'da ticaret akımları oynaklığının nedeninin ekonomik büyümeden kaynaklandığı iddia edilememektedir. Ancak net ticaret ve ekonomik büyüme arasında eş-bütünleşik bir ilişki vardır. ASEAN serbest ticaret anlaşması sadece bölgedeki üretim faaliyetlerini kolaylaştırmamış aynı zamanda ticari ve ekonomik bütünleşmeyi de sağlamıştır. Uzaklık gibi coğrafi etkenler ve yoğun ticaret akımları ile birlikte bir çok ekonomik etken bütünleşmeyi hızlandırmıştır. 
$\mathrm{Bu}$ durum toplam talep bileşeninin en oynak ithalat ve ihracat bileşenleri üzerinde de bu bağlamda etkili olmuştur yani elde dilen sonuçlar bütünleşme hızı ile de doğru orantılıdır. Her ne kadar ticaret akımlarının bir serbest ticaret anlaşması ya da ekonomik bir birliğe üye olan ülkeler için daha dengeli hale geldiği literatürde iddia edilse de seçili ülke grubu için bu iddia kabul edilememektedir. İleri de bu alanda yapıcalak çalışmalar için bu durumun dikkate alınması bir katkı olacaktır. Ayrıca ASEAN'ın şu anda gözlemci konumunda olan ve heniz ticaret engelleri ve tarifelerini kaldırmamış olan pek çok üyesi mevcuttur. Bu ülkelerinde serbest ticaret antlaşmasını imzalaması ile dengelerin nasıl değişeceği de başka bir çalışmaya konu edilebilir.

\section{KAYNAKÇA}

ABBOTT, F. M. (2000). 'NAFTA and the legalization of world politics: A case study'. International Organization, 54 (3): 519-547.

BAUM, C. F. ve ÇAĞLAYAN, M. (2008). 'The volatility of international trade flows and exchange rate uncertanity', European Economic Review, 36(6): 1311-1321.

BARKOULAS, J., BAUM, C. F. ve ÇAĞLAYAN, M. (2002). ''Exchange rate effects on the volume and variability of trade flows', Journal of International Money and Finance, 21: 481-496.

BEAUDRY, P. ve PORTIER, F. (2005). ' When can changes in expectations cause business cycle fluctuations in Neo-classical settings?’, NBER Working Papers, No. 10776.

BENNETT, F., LEDERMAN, D., PIENKNAGURA, S. ve ROJAS, D. (2016). "The volatility of international trade flows in the 21 st century. Whose fault is it anyway?', World Bank Group, Policy Research Working Paper, No. 7781.

BREUSCH, T. S. ve PAGAN, A. R. (1980). 'The lagrange multiplier test and its application to model specifications in econometrics", Review of Economic Studies. 47: 239-253.

DI GIOVANNI, J. ve LEVCHENKO, A. (2009). "Trade openness and volatility", The Review of Economics and Statistics, 91(3): 558-585.

ENGEL, C. ve WANG, J. (2008). ''International trade in durable goods: Understanding volatility, cyclicality and elasticities', NBER Working Papers, No. 13814.

GÜLOĞLU, B. ve İVRENDİ, M. (2010). '’Output fluctuations: transitory or permanent? The case of Latin America', Applied Economics Letters, 17: 381-386.

HATEMI_J, A. (2011). 'Asymmetric panel causality tests with an application to the impact of fiscal policy on economic performance in Scandinavia', Munich Personal RePEc Archive,https://mpra.ub.uni-muenchen.de/55527/1/MPRA_paper_55527.pdf, 10.11.2018.

HATEMI-J, A., AJMI, N., GHASSEN, A,.EL MONTANESSER, LOTS, R. İ. ve GUPTA, R. (2015). ' 'Research output and economic growth in G7 Countries: new evidence from asymmetric panel causality testing', Applied Economics, November, 1-8.

HATEMI-J, A. ve EL-KHATIB, Y. (2016). ' An extension of the asymmetric causality tests for dealing with deterministic trend components", Applied Economics, 48(42): 40334041. 
MANSFILED, E. D. ve REINHARDT, E. (2008). International institutions and the volatility of international trade, International Organization, 62(4): 621-652.

SOLEYMANI, A., CHUA, S. Y. ve HAMAT, A. F. C. (2015). ''Exchange rate volatility and ASEAN-4's trade flows: is there a third country effect?', International Economics and Economic Policy, 14(1): 91-117.

PRAJAKSCHITT, P. (2015). Exchange rate volatility and trade: The case of trade among China and ASEAN-6, Lund University, School of Economics and Management, published Master Essay, August, http://lup.lub.lu.se/luur/download?func=downloadFile \&recordOId=7793864\&fileOId $=7793877,13.11 .2018$.

PESARAN H. M. (2004). 'General diagnostic tests for cross section dependence in panels', Working Paper No:0435, University of Cambridge.

PESARAN, H. M. (2006). ''Estimation and inference in large heterogeneous panels with a multifactor error structure', Econometrica, 74(4): 967-1012.

PESARAN, H. M. (2007). "'A Simple panel unit root test in the presence of cross section dependence.” Journal of Applied Econometrics, 22(2): 265-312.

PESARAN, H. M. (2013). 'Large panel data models with cross-sectional dependence: A survey. A Course on Panel Data Models", University of Cambridge, 1-67.

PESARAN, H. M. ve YAMAGATA, T. (2008). "Testing slope homogeneity in large panels', Journal of Econometrics, 142: 50-93.

PINO, G., TAŞ, D. ve SHARMA, S. C. (2016). ' An investigation of the effects of exchange rate volatility on exports in East Asia', Applied Economics, 48(26): 2397-2411, DOI: 10.1080/00036846.2015.1122730.

ROSE, A. K. (2000). “One money, one market: The effect of common currencies on trade”, Economic Policy, 15: 9-45.

RAHUTAMI, A. I. (2013). Real exchange rate volatility and internatonal trade: ASEAN expreience towards ASEAN economic community. NICE \& Discon Research Seminars,

https://www.ru.nl/publish/pages/718686/exchange_rate_and_trade_nsm_conference.p df, 13.11.2018.

WESTERLUND, J. (2008). "Panel Co-integration Tests of The Fisher Effect." Journal of Applied Econometrics, 23:193-233.

ZIMMERMAN, C. (1999). 'International business cycles and exchange rates', Review of International Economics, 7(4): 682-98. 